\title{
KARAKTERISTIK HEAT COLECTOR TIPE SOLENOID CELUP
}

\author{
Burhan Liputo $^{1)}$, Arif Murtaqi Akhmad Mutsyahidan ${ }^{2)}$ \\ ${ }^{1}$ Program Studi Mesin dan Peralatan Pertanian, Politeknik Gorontalo \\ ${ }^{2}$ Program Studi Teknologi Hasil Pertanian, Politeknik Gorontalo \\ Email: burhanliputo@poligon.ac.id ${ }^{1)}$
}

\begin{abstract}
ABSTRAK
Kolektor panas (Heat Colector) tipe solenoid celup adalah salah satu bagian komponen pada boiler penghangat ayam ternak yang berfungsi sebagai penyimpan panas untuk dimanfaatkan sebagai pemanas atau penghangat. Komponen kolektor ini terdiri dari pipa solenoid, air penyimpan panas, pipa udara, pipa air dan sensor pendeteksi panas. Prinsip penyimpanan panas pada kolektor adalah melalui proses konveksi dari pembakaran material tongkol di dalam boiler (tungku). Panas konveksi ini akan menyebabkan air di dalam kolektor menjadi panas dan akan tersimpan dalam waktu tertentu, sekaligus terkonduksi pada pipa solenoid yang letak posisinya tercelup. Keadaan ini menyebabkan ruang sepanjang pipa solenoid menjadi panas dan akan digunakan untuk memanaskan hembusan udara yang akan dialirkan menuju ruang ternak ayam. Keadaan suhu ruang pada kolektor dapat dideteksi menggunakan sensor thermocouple dan nilai temperatur yang dihasilkan akan ditampilkan melalui display thermostat. Hasil penelitian menunjukkan bahwa temperatur maksimum pada kolektor solenoid mencapai $89{ }^{\circ} \mathrm{C}$ dalam waktu pemanasan 2,3 jam dan waktu penyimpanan 5,3 Jam dengan suhu yang distabilkan pada kisaran (36-37) ${ }^{\circ} \mathrm{C}$. Sehingga akumulasi kemampuan kolektor solenoid untuk mensuplai suhu dapat bertahan dalam waktu 7,6 Jam. Kolektor tipe solenoid dirancang dengan tahapan-tahapan metode kerja yaitu desain dan analisis konsep, pembuatan konstruksi, pengujian dan evaluasi kinerja.
\end{abstract}

Kata kunci: Boiler, Heat colector, Pipa solenoid, Tongkol jagung.

\section{ABSTRACT}

A solenoid dip type heat collector is one of the component parts in a chicken warmer boiler that functions as heat storage for use as a heater or heater. This collector component consists of solenoid pipes, heat storage water, air pipes, water pipes, and heat detection sensors. The principle of heat storage in the collector is through the process of convection from the combustion of cob material in the boiler (furnace). This convection heat will cause the water in the collector to become hot and will be stored for a particular time, as well as conduction in a solenoid pipe whose position is immersed. This situation causes the space along the solenoid pipe to become hot and will be used to heat the gusts of air that will flow into the chicken farm. The condition of the room temperature in the collector can be detected using a thermocouple sensor, and the resulting temperature value will be displayed via the thermostat display. The results showed that the maximum temperature in the solenoid collector reached $89^{\circ} \mathrm{C}$ in a heating time of 2.3 hours and a storage time of 5.3 hours with a heat stabilized in the range (36-37) ${ }^{\circ}$ C. So that the accumulation of solenoid collector's ability to supply temperatures can last within 7.6 hours. Solenoid type collectors were designed with stages of work methods, namely concept design and analysis, construction, testing, and performance evaluation.

\section{Keywords: Boilers, Heat collector, Solenoid pipes, Corncobs.}

\section{PENDAHULUAN}

Secara umum boiler dapat diklasifikasikan menjadi dua jenis yaitu boiler stasioner dan boiler mobil. Boiler stasioner ialah boiler yang didudukkan diatas pondasi yang tetap, seperti boiler untuk pembangkit tenaga, untuk industri dan lain-lain. Boiler mobil adalah boiler yang dipasang pada pondasi yang berpindah-pindah (mobile) seperti boiler lokomotif, loko mobil dan termasuk boiler kapal [1]. Ketel uap (boiler) adalah sebuah alat untuk menghasilkan uap yang terdiri atas dua bagian penting yaitu dapur pemanasan bahan bakar dan boiler proper untuk mengubah air menjadi uap [4].

Konduktivitas panas yang diartikan sebagai kemampuan suatu materi untuk menghantarkan panas, merupakan salah satu parameter yang diperlukan dalam sifat karakteristik suatu material. Pada kebanyakan pengerjaan,diperlukan pemasukan atau pengeluaran kalor,untuk mencapai dan mempertahankan keadaan yang dibutuhkan sewaktu proses berlangsung. Kondisi pertama yaitu mencapai keadaan yangdibutuhkan untuk pengerjaan, bila pengerjaan harus berlangsung pada suhu tertentu dan suhu ini harus dicapai dengan jalan pemasukan atau pengeluaran ka1or. Kondisi kedua yaitu mempertahankan keadaan yang dibutuhkan untuk operasi proses, terdapat pada pengerjaan eksoterm dan endoterm. Disamping perubahan secara kimia, keadaan ini dapat juga merupakan pengerjaan secara alami. Pada pengembunan dan kristalisasi ka1or harus dikeluarkan. Pada penguapan dan pada 
umumnya pada pelarutan, ka1or harus dimasukkan [3].

Pipa kalor terdiri dari tabung hampa yang pada kedua ujungnya ditutup dan diisi dengan fluida lalu dipanaskan di ujung pipa pada suhu yang diinginkan. Salah satu ujung pipa kalor dicelupkan ke heater (evaporator) dan ujung lainnya diberi pendingin (kondensor). Tujuannya adalah untuk mentransfer panas melalui pipa dari evaporator ke kondensor. Banyak peneliti menyelidiki karakteristik dan parameter pipa panas baik secara eksperimen dan theoretically[5].

Boiler penghangat adalah mesin yang dapat membangkitan panas menggunakan bahan bakar limbah tongkol jagung dengan sistem pengaturan dan pengendalian sirkulasi aliran panas dalam tabung pipa solenoid untuk dimanfaatkan sebagai penghangat ayam ternak jenis pedaging. Sistem ini terdiri atas beberapa bagian utama yaitu unit tungku, kolektor solenoid, blower, dan panel kendali aliran panas. Berikut adalah fisik boiler hasil rancangan dalam penelitian :

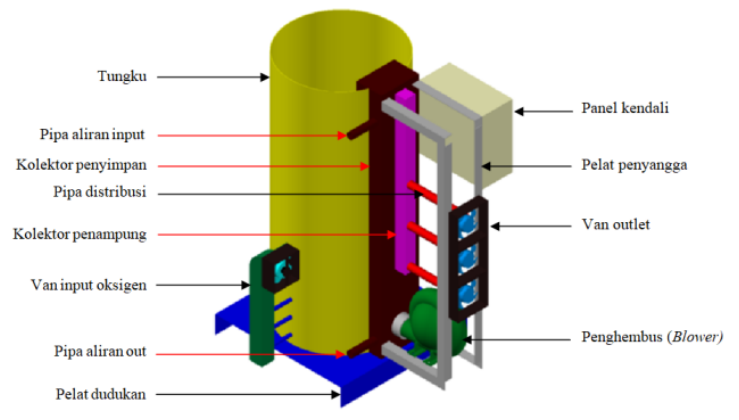

Gambar 1. Boiler penghangat ayam ternak

Heat colector atau kolektor panas tipe solenoid adalah Salah satu bagian dalam perancangan konstruksi pada penelitian tentang boiler penghangat ayam ternak yang menggunakan bahan bakar limbah tongkol jagung. unit ini merupakan bagian penting dalam sistem boiler penghangat ayam ternak, karena memiliki konsep penyimpan panas dalam waktu tertentu dan penstabil aliran panas pada keluaran secara otomatis.

Kolektor panas tipe solenoid dirancang menggunakan pipa berbentuk solenoid yang terbuat dari bahan tembaga dengan prinsip konstruksi celup atau rendam yang menggunakan media air sebagai penyimpan panas. Konstruksi ini dimaksudkan untuk mengoptimalkan fungsi penyimpanan panas dari hasil pembakaran material tongkol di dalam tungku boiler.

Tujuan pengembangan kolektor panas tipe solenoid adalah untuk memaksimalkan fungsi boiler penghangat pada aspek penyimpan panas, pengaturan aliran dengan memanfaatkan limbah tongkol jagung sebagai bahan bakar utama pengganti bahan bakar gas LPG yang digunakan peternak ayam di Gorontalo. Tahapan metode pengembangan kolektor tipe solenoid pada boiler penghangat adalah membuat desain dan analisis konsep, membuat konstruksi, menguji dan mengevaluasi hasil uji fungsi kolektor.

Pengembangan ini diharapkan menjadi solusi yang praktis dan ekonomis bagi masyarakat Gorontalo untuk beralih pola dari kebiasaan menggunakan bahan bakar gas LPG ke pemanfaatan limbah tongkol jagung yang melimpah.

\section{METODE PELAKSANAAN}

Kolektor solenoid dirancang dengan tahapantahapan metode sebagai berikut.

\subsection{Desain dan Analisis Konsep}

Tahapan desain dan analisis didasarkan pada prinsip kerja dan fungsi bagian-bagian utama kolektor solenoid seperti badan kolektor, pipa solenoid, air penyimpan dan saluran inlet atau outlet untuk aliran air. Anasilis difokuskan pada karakeristik konstruksi, efektivitas penyimpan, dan sistem pengaturan aliran panas. Berikut adalah konsep dasar yang menggambarkan suatu unit kolektor tipe solenoid :

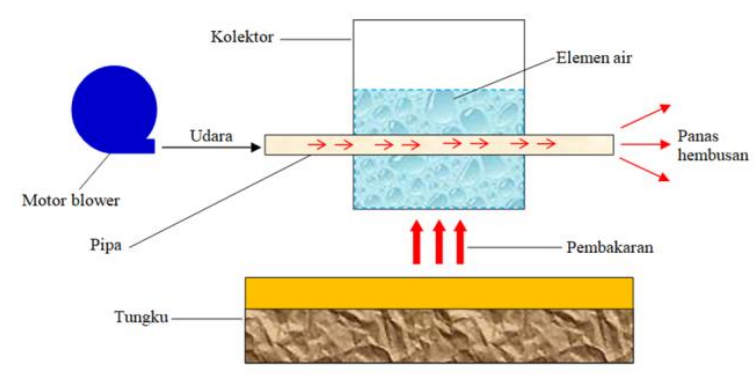

Gambar 2. Konsep dasar kolektor

Gambar 2 menjelaskan bahwa prinsip dasar penyimpan panas pada kolektor dilakukan dengan beberapa tahap yaitu konduksi panas hasil pembakaran tongkol dalam tungku pada badan kolektor, proses pengumpul panas menggunakan air untuk disimpan, proses konduksi panas air ke badan pipa dan proses mengalirkan udara ke dalam pipa. Tahapan-tahapan ini akan sangat tergantung pada proses pembakaran tongkol di dalam tungku boiler sehingga harus menjadi perhatian dalam menganalisis.

Teori menjelaskan bahwa pembakaran adalah reaksi kimia yang cepat antara oksigen dan bahan yang dapat terbakar yang menghasilkan kalor [9]. Pembakaran yang sempurna akan dapat mengubah seluruh energi yang memungkinkan pada bahan bakar. Akan tetapi pada kenyataannya pembakaran sempurna dengan efisiensi $100 \%$ sangat sulit tercapai akibat kerugian (Loss) pada instrumen pendukung [2].

Selain itu desain konstruksi unit kolektor solenoid akan memperhatikan keadaan dan karaketistik boiler dengan tujuan agar panas 
pembakaran di dalam tungku dapat diserap dan disimpan secara efektif dan optimal. Ada dua hal yang harus diperhatikan dalam desain konstruksi yaitu penggunaan material dan dimensi fisik rancangan kolektor yang akan dibangun.

\subsection{Pembuatan Konstruksi}

Tahap membuat konstruksi kolektor dimulai pada pembuatan pola komponen, pembentukan komponen, penempatan dan perakitan. Bagianbagian komponen kolektor yang dibuat adalah badan kolektor, pipa solenoid, pipa saluran, dudukan sensor, rangkaian pengatur suhu dan instrumen ukur.

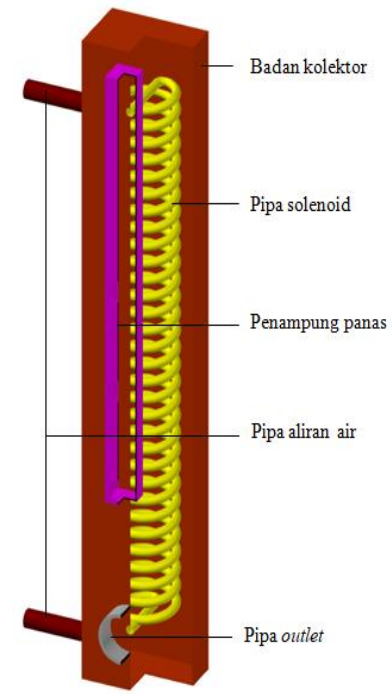

Gambar 3. Konstruksi kolektor solenoid

Konstruksi badan kolektor dibuat menggunakan material besi pelat jenis eisel dengan dimensi tebal $1,2 \mathrm{~mm}$ dan volume ruang $13.500 \mathrm{~cm}^{3}$. Kolektor solenoid berbentuk persegi panjang pada posisi pemasangan secara vertikal dan sebagaian badan kolektor menempel pada bagian dalam tungku pembakaran boiler. fungsi Badan kolektor adalah untuk menempatkan komponen-komponen bagian dari kolektor baik di dalam maupun di luar agar menjadi satu kesatuan fungsi kolektor.

Pipa solenoid dibuat dari bahan pipa tembaga yang memiliki dimensi tebal $2 \mathrm{~mm}$, dimensi tinggi 73 $\mathrm{cm}$ dan diameter $12 \mathrm{~mm}$ dengan bentuk konstruksi spiral solenoid. Pipa solenoid berfungsi untuk memanaskan udara yang dialirkan ke dalam pipa menuju ruang ternak melalui proses konveksi panas.

\section{Gambar 4. Dimensi kolektor solenoid}

\subsection{Pengujian dan Evaluasi Kinerja}

Kinerja kolektor solenoid dapat diamati dan diketahui melalui evaluasi hasil pengujian secara langsung dengan menggunakan bahan bakar tongkol jagung. Aspek yang diuji meliputi tingkat kebocoran kolektor, kemampuan menyimpan panas, lama waktu penyimpanan, panas keluaran, dan fungsi kendali aliran panas udara pada keluaran. Berdasarkan evaluasi data-data uji aspek ini dapat menentukan fungsi dan kinerja kolektor solenoid. Aspek yang penting diperhatikan adalah kemampuan kolektor untuk menyimpan energi panas dalam waktu yang cukup lama dan mampu mengatasi pelepasan panas pada lingkungan.

Sebagaimana dijelaskan dalam referensi bahwa, fenomena berkurangnya fluida yang menguap menyebabkan perpindahan panas kurang maksimum begitu pula saat pendingin yang dibuat terlalu berlebihan. Dan dampaknya begitu signifikan pada batas operasi dari pipa kalor [Ma, H. B. and Peterson, G. P4]. Faktor-faktor yang mempengaruhi nilai efisiensi boiler antara lain mass flow, tekanan dan temperatur uap masuk boiler, serta tekanan dan temperatur uap keluar boiler [4].

\subsection{Diagram Alir Penelitian}

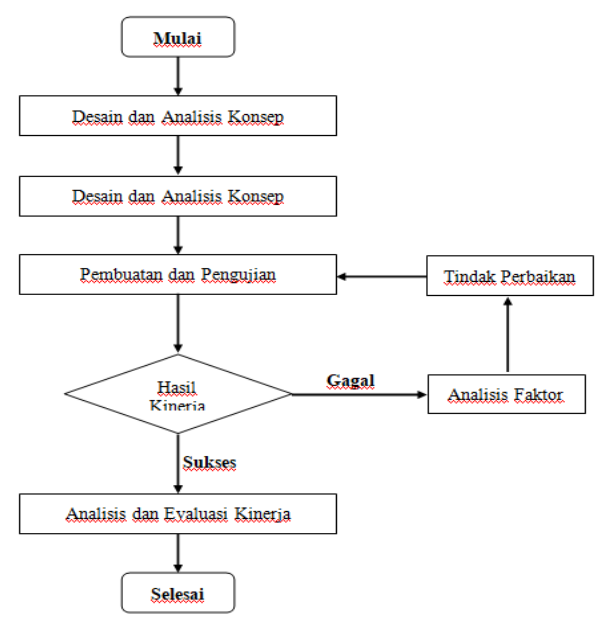

Gambar 5. Skema alir penelitian

\section{HASIL DAN PEMBAHASAN}


Pembahasan hasil penelitian dalam publikasi ini akan menjelaskan karakteristik kinerja sistem kolektor solenoid melakukan kerja untuk menghasilkan energi panas penghangat sebagai pengganti bahan bakar gas LPG pada peternak ayam di masyarakat. Secara khusus penjelasan ini pada batas aspek karakteristik pembangkitan panas, Penyimpanan, pelepasan dan pengaturan stabilitas suhu panas keluaran dari kolektor solenoid.

\subsection{Pembangkitan Suhu Kolektor}

Pada prinsipnya panas yang dibangkitkan dan disimpan di dalam kolekor solenoid merupakan efek proses konduktivitas pembakaran material tongkol jagung pada tungku boiler yang menyebabkan air di dalam kolektor menjadi panas. Pembangkitan panas pada tungku boiler hingga pada kolektor melalui beberapa tahapan proses heat trnsfer yaitu proses konveksi dari pembakaran pada badan kolektor, proses konduksi dari badan kolektor kemedia air penyimpan, proses konduksi dari median air ke pipa solenoid, dan proses konvesi dari pipa solenoid ke udara yang dialirkan ke dalam pipa solenoid yang dilewatinya. Proses konduksi dan pembangkitan panas pada kolektor membutuhkan waktu selam 2,2 Jam untuk mencapai suhu maksimum $89{ }^{\circ} \mathrm{C}$ dengan perubahan rata-rata suhu sebesar $6,6^{\circ} \mathrm{C}$ dari suhu awal $36{ }^{\circ} \mathrm{C}$. Berikut data suhu dan waktu pembangkitan panas pada kolektor solenoid :

Tabel 1. Suhu Pembangkitan pada Kolektor :

\begin{tabular}{cccc}
\hline \multicolumn{4}{c}{ Pembangkitan Suhu Pada Kolektor } \\
\hline $\begin{array}{c}\text { Tahapan } \\
\text { Waktu } \\
\text { (menit) }\end{array}$ & $\begin{array}{c}\text { Waktu } \\
\text { Pengamata } \\
\mathbf{n}\end{array}$ & $\begin{array}{c}\text { Suhu } \\
\text { Masuk } \\
\mathbf{T}_{\mathbf{1}} \\
\left({ }^{\circ} \mathbf{C}\right)\end{array}$ & $\begin{array}{c}\text { Suhu Keluar } \\
\mathbf{T}_{\mathbf{2}} \\
\left({ }^{\circ} \mathbf{C}\right)\end{array}$ \\
\hline 0 & 16.00 .18 & 36 & 36 \\
20 & 16.20 .03 & 42 & 36 \\
40 & 16.39 .48 & 53 & 36 \\
60 & 16.59 .53 & 68 & 37 \\
80 & 17.19 .22 & 77 & 41 \\
100 & 17.30 .03 & 84 & 44 \\
120 & 17.59 .48 & 86 & 45 \\
140 & 18.20 .04 & 89 & 45 \\
\hline
\end{tabular}

Data Tabel 1 menjelaskan karakteristik pembangkitan panas kolektor dari tahap waktu 0 menit dengan suhu awal $\mathrm{T}_{1}=36^{\circ} \mathrm{C}$ dan suhu keluaran $\mathrm{T} 2=36{ }^{\circ} \mathrm{C}$. Menit ke 60 terjadi perubahan suhu $\mathrm{T}_{1}$ dan $\mathrm{T}_{2}$ yaitu 68 dan $37^{\circ} \mathrm{C}$. Kondisi ini masih kategori normal karena suhu keluaran $\mathrm{T}_{2}$ masih dalam batas jarak suhu normal yang dibutuhkan ayam ternak. Pada menit ke 80 sampai dengan menit ke 140 terjadi peningkatan panas kolektor yaitu $\mathrm{T}_{1}=89{ }^{\circ} \mathrm{C}$ dan $\mathrm{T}_{2}$ $=45^{\circ} \mathrm{C}$. Kondisi ini harus diperhatikan karena sudah masuk dalam zona merah atau zona yang harus di kontrol. Berikut grafik karakteristik zona normal dan zona merah :

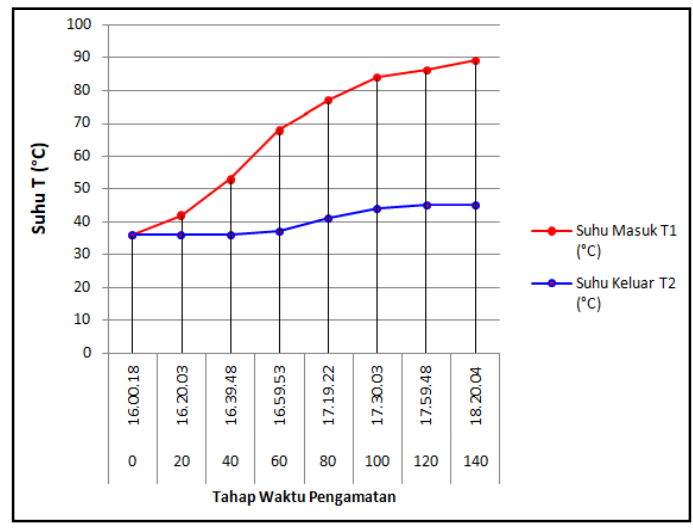

Gambar 6. Karakteristik suhu $T_{1}$ dan $T_{2}$.

Gambar 6 menjelaskan bahwa proses peningkatan suhu kolektor pada pembangkitan panas telah mencapai batas maksimum pada menit ke 140 dengan suhu masuk $\mathrm{T}_{1}$ mencapai $89{ }^{\circ} \mathrm{C}$ dan suhu keluar $\mathrm{T}_{2}$ sebesar $45{ }^{\circ} \mathrm{C}$. Temperatur ini melebihi batas maksimum yang dibutuhkan maka harus dilakukan kontrol penstabil agar dampak yang ditimbulkan tidak akan berpengaruh terhadap suhu keluaran dari kolektor penyimpan panas untuk dimanfaatkan.

\subsection{Kontrol Peningkatan Suhu}

Suhu maksimum yang dibangkitkan dalam kolektor solenoid membutuhkan waktu 2,3 jam atau sekitar 140 menit. Suhu kolektor yang mencapai batas maksimum $89^{\circ} \mathrm{C}$ pada dasarnya akan sejalan dengan peningkatan suhu keluaran kolektor. Sehingga kondisi ini harus diantisipasi agar tidak melebihi suhu penghangat dan tetap terjaga pada suhu normal. Antisipasinya adalah dengan mengontrol kisaran batas suhu yang dialirkan masuk ke dalam saluran pipa solenoid yaitu maksimum 45 ${ }^{\circ} \mathrm{C}$. Berikut karakteristik kontrol motor penstabil :

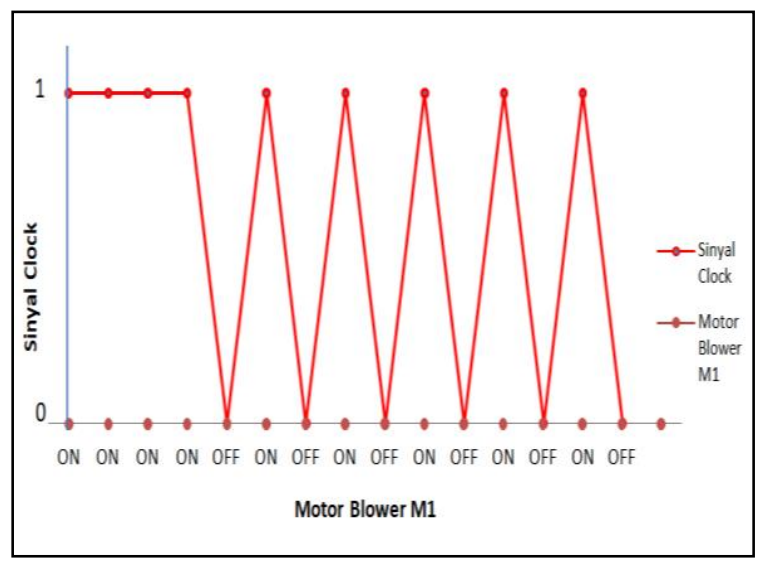

Gambar 7. Sinyal kontrol motor 
Berikut tabel penjelasan sinyal kontrol penstabil pada Gambar 7:

Tabel 2. Analogi Sinyal Kontrol Penstabil :

\begin{tabular}{cccc}
\hline \multicolumn{4}{c}{ Karakterisitik Kontrol Suhu Terima Kolektor } \\
\hline $\begin{array}{c}\text { Motor } \\
\text { Blower } \text { M }_{\mathbf{1}}\end{array}$ & $\begin{array}{c}\text { Waktu Set } \\
\text { (detik) }\end{array}$ & $\begin{array}{c}\text { Sinyal } \\
\text { Clock }\end{array}$ & $\begin{array}{c}\text { Suhu } \\
\text { Keluar } \mathbf{T}_{\mathbf{2}} \\
\mathbf{(}^{\circ} \mathbf{C} \text { ) }\end{array}$ \\
\hline ON & ON & 1 & 35 \\
ON & ON & 1 & 36 \\
ON & ON & 1 & 36 \\
ON & ON & 1 & 37 \\
OFF & 10 & 0 & 41 \\
ON & 10 & 1 & 41 \\
OFF & 10 & 0 & 41 \\
ON & 10 & 1 & 44 \\
OFF & 10 & 0 & 44 \\
ON & 10 & 1 & 44 \\
OFF & 10 & 0 & 45 \\
ON & 10 & 1 & 45 \\
OFF & 10 & 0 & 45 \\
ON & 10 & 1 & 45 \\
OFF & 10 & 0 & 45 \\
\hline
\end{tabular}

Prinsip kontrol penstabil suhu pada Tabel 2 menjelaskan bahwa kerja motor blower $\mathrm{M}_{1}$ sebagai penghembus udara ke dalam pipa solenoid akan tidak kontinyu atau terkonter. Maksudnya adalah motor akan ON dan akan OFF dalam selang waktu 10 detik yaitu 10 detik ON dan 10 detik OFF. Prinsip ini digunakan untuk mereduksi panas udara dalam pipa solenoid yang akan keluar dari kolektor untuk dimanfaatkan.

\subsection{Pelepasan Suhu Kolektor}

Setelah mencapai suhu maksimum kolektor sebesar $89{ }^{\circ} \mathrm{C}$, maka secara alamiah suhu tersimpan ini akan megalami penurunan atau pelepasan panas ke lingkungan. Kondisi ini akan seiring saat material bahan bakar tongkol di dalam tungku boiler telah habis dan proses pembakaran selesai. Begitu pula batas suhu maksimum yang diizinkan akan perlahan mengalami penurunan. Berikut data penurunan suhu tersimpan dalam kolektor :

Tabel 3. Suhu Kolektor dan Penurunan :

\begin{tabular}{|c|c|c|c|}
\hline \multicolumn{4}{|c|}{ Konduksi Panas Pembakaran Pada Kolektor Boiler } \\
\hline $\begin{array}{c}\text { Tahapan } \\
\text { Waktu } \\
\text { (menit) }\end{array}$ & $\begin{array}{c}\text { Waktu } \\
\text { Pengamatan }\end{array}$ & $\begin{array}{c}\text { Suhu } \\
\text { Tersimpan } \\
\Delta \mathrm{T} \\
\left({ }^{\circ} \mathrm{C}\right) \\
\end{array}$ & $\begin{array}{c}\text { Suhu } \\
\text { Keluar } \\
\mathbf{T}_{2} \\
\left({ }^{\circ} \mathbf{C}\right) \\
\end{array}$ \\
\hline 160 & 18.40 .02 & 89 & 45 \\
\hline 180 & 18.59 .28 & 88 & 45 \\
\hline 200 & 19.19 .54 & 87 & 46 \\
\hline 220 & 19.40 .20 & 83 & 46 \\
\hline 240 & 20.00 .06 & 73 & 42 \\
\hline 260 & 20.20 .02 & 70 & 42 \\
\hline 280 & 20.39 .58 & 68 & 42 \\
\hline 300 & 21.00 .09 & 65 & 37 \\
\hline 320 & 21.20.01 & 63 & 37 \\
\hline
\end{tabular}

\begin{tabular}{llll}
\hline 340 & 21.40 .06 & 57 & 37 \\
360 & 22.00 .03 & 54 & 37 \\
380 & 22.19 .37 & 51 & 37 \\
400 & 22.40 .11 & 46 & 36 \\
420 & 23.00 .22 & 44 & 36 \\
440 & 23.20 .05 & 39 & 36 \\
460 & 23.39 .57 & 36 & 36 \\
\hline
\end{tabular}

Data Tabel 3 menunjukkan perubahan penurunan suhu kolektor dari maksimum $89{ }^{\circ} \mathrm{C}$ menjadi $36^{\circ} \mathrm{C}$ atau kembali pada kondisi suhu awal. Waktu yang dibutuhkan perubahan suhu maksimum ke suhu awal adalah sekitar 5 jam atau pada menit ke 460. Pada menit ke 160 sampai menit ke 280 merupakan zona dimana sistem kontrol penstabil dalam keadaan aktif atau sedang bekerja. Artinya proses kendali ON dan OFF motor blower $\mathrm{M}_{1}$ masih dalam keadaan bekerja untuk kondisi penurunan suhu dalam selang waktu 140 menit atau sekitar 2,3 jam. Menit ke 300 sampai menit ke 460 sistem kontrol penstabil akan non-aktif atau tidak bekerja, artinya motor blower $\mathrm{M}_{1}$ akan tetap ON. Berikut adalah karakteristik motor blower $\mathbf{M}_{1}$ dalam keadaan aktif pada proses penurunan suhu kolektor :

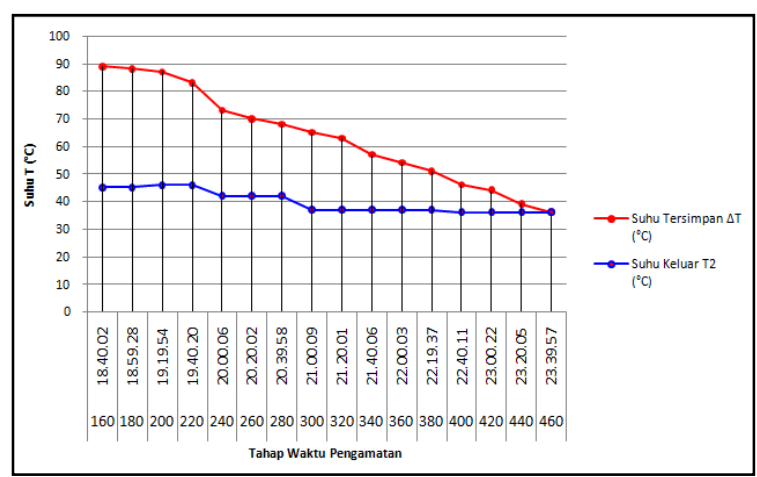

Gambar 7. Karakteristik penurunan suhu kolektor

Pada Gambar 7 dapat diamati grafik penurunan suhu kolektor (garis merah) yang cenerung menurun dan grafik suhu keluaran (garis biru) yang relatif stabil. Daerah antara garis biru dan garis merah merupakan zona suhu yang masuk dalam fungsi kontrol untuk distabilkan. Berikut adalah karakteristik sinyal kontrol motor blower $\mathrm{M}_{1}$ aktif selama zona penurunan :

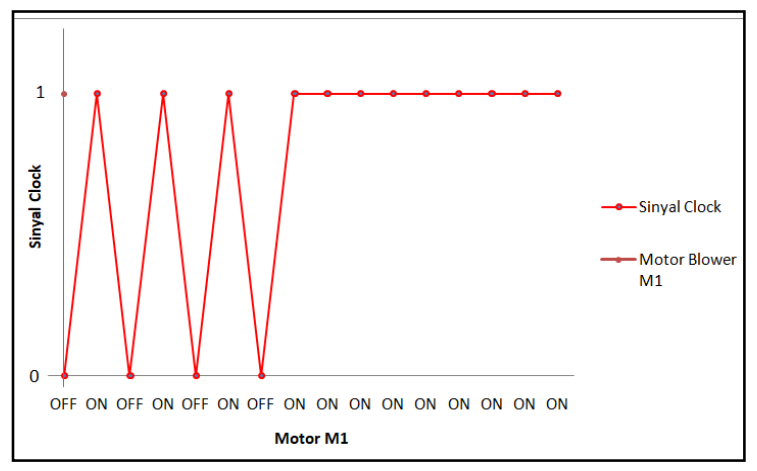

Gambar 8. Karakteristik kontrol motor blower $\mathbf{M}_{1}$. 
Tabel 4 menjelaskan analogi kontrol motor penstabil bekerja.

Tabel 4. Analogi Sinyal Penstabil Suhu Menurun :

\begin{tabular}{|c|c|c|c|}
\hline \multicolumn{4}{|c|}{ Pelepasan Panas Kolektor } \\
\hline $\begin{array}{c}\text { Motor } \\
\text { Blower } \mathrm{M}_{1}\end{array}$ & $\begin{array}{c}\text { Waktu Set } \\
\text { (detik) }\end{array}$ & $\begin{array}{l}\text { Sinyal } \\
\text { Clock }\end{array}$ & $\begin{array}{c}\text { Suhu Keluar } \\
\mathbf{T}_{2} \\
\left({ }^{\circ} \mathbf{C}\right) \\
\end{array}$ \\
\hline OFF & 10 & 0 & 45 \\
\hline ON & 10 & 1 & 45 \\
\hline OFF & 10 & 0 & 46 \\
\hline ON & 10 & 1 & 46 \\
\hline OFF & 10 & 0 & 42 \\
\hline ON & 10 & 1 & 42 \\
\hline OFF & 10 & 0 & 42 \\
\hline ON & ON & 1 & 37 \\
\hline ON & ON & 1 & 37 \\
\hline ON & ON & 1 & 37 \\
\hline ON & ON & 1 & 37 \\
\hline ON & ON & 1 & 37 \\
\hline ON & ON & 1 & 36 \\
\hline ON & ON & 1 & 36 \\
\hline ON & ON & 1 & 36 \\
\hline ON & ON & 1 & 36 \\
\hline
\end{tabular}

\section{KESIMPULAN DAN SARAN}

Dapat dikutip kesimpulan dan saran hasil penelitian pada aspek karakteristik heat colector tipe solenoid celup adalah berikut ini :

\subsection{Kesimpulan}

Mengamati karakteristik fungsi kolektor solenoid dengan kesmpulan sebagai berikut :

1. Fungsi utama komponen kolektor tipe solenoid celup pada boiler penghangat adalah untuk menyimpan panas dan sebagai sumber panas boiler.

2. Kolektor solenoid tipe celup mampu menyimpan panas selama 7, 6 jam dengan capaian suhu maksimum $89^{\circ} \mathrm{C}$.

3. Proses pembangkit panas kolektor membutuhkan waktu 2,3 jam dan proses penurunan suhu dalam waktu 5,3 jam sampai pada suhu awal $36^{\circ} \mathrm{C}$.

4. Kisaran suhu maksimum untuk kontrol penstabil adalah $36-45^{\circ} \mathrm{C}$.

5. Kontrol penstabil bekerja pada kondisi zona kenaikan suhu dengan waktu 1,3 jam dan zona penurunan suhu dengan waktu 2,3 jam.

\subsection{Saran}

Kolektor panas tipe solenoid celup dapat dikembangkan dengan meningkatkan volume ruang kolektor sehingga kapasitas waktu penyimpanan dapat bertahan lebih lama.

\section{DAFTAR PUSTAKA}

Effendy, D. A. (2013). Rancang Bangun Boiler Untuk Proses Pemanasan Sistem Uap Pada
Industri Tahu Dengan Menggunakan Catia V5. Malang: Universitas Negeri Malang.

Ma, H. B. (1998). The Minimum Meniscus Radius and Capillary Heat Transport Limit in Micro Heat Pipes. "J. Heat Transfer, 120.

Putri, A. (2008). Sistem Boiler. Surabaya: Institut Teknologi Sepuluh Nopember.

Ristyanto, A. N. (2013). Simulator Perhitungan Efisiensi Sistem Pembangkit Listrik Tenaga Uap (PLTU) Rembang. ejournals1.undip.ac.id/index.php/transient/ article/vie.

Ruben Siregar, R. I. (2016, Oktober ). Pengaruh Perpindahan Panas Pipa Kalor Pada Posisi HorizontaVolume. FTEKNIK, 3.

Sucipto, T. P. (2013, April ). Analisa Konduktivitas Termal Baja St-37 dan Kuningan. 9 No. 1, 13-17.

Sutikno, D. S. (2011). Study On Pressure Distribution In The Blade Passage Of The Francis Turbine. Rekayasa Mesin, 154-158.

Tourniera, J. M.-G. (1994, March ). A heat pipe transient analysis odel . International Journal of Heat and Mass Transfer, 37(pp. 5), 753-762.

Winanti, w. S. (2006). Perhitungan Efisiensi Boiler Pada Industri Industri Tepung Terigu. Jurnal Teknik Lingkungan, 58 - 65.

Yolanda Pravitasari, M. B. (2017). Analisis Efisiensi Boiler Menggunakan Metode Langsung. Prisma Fisika, V, No. 01, 09-12. 